\title{
Trends in dietary intakes of vitamins $A, C$ and $E$ among Japanese men and women from 1974 to 2001
}

\author{
Yoshimi Kato ${ }^{1}+$, Satoyo Ikehara ${ }^{2}$, Koutatsu Maruyama², Mieko Inagawa ${ }^{3}$, \\ Miyuki Oshima ${ }^{3}$, Kimiko Yokota ${ }^{2}$, Taeko Yamazaki ${ }^{4}$, Masa Kishi ${ }^{4}$, Sachiko Murai ${ }^{4}$, \\ Mitsumasa Umesawa ${ }^{2}$, Enbo Ma $^{2}$, Kazumasa Yamagishi ${ }^{2}$, Takeshi Tanigawa ${ }^{2} \ddagger$, \\ Michinori Kurokawa ${ }^{5}$, Shinichi Sato ${ }^{5,}$, Takashi Shimamoto ${ }^{5}$ and Hiroyasu Iso ${ }^{2, *}$ \\ 'Department of Public Health Medicine, Graduate School of Comprehensive Human Sciences, Institute of \\ Community Medicine, University of Tsukuba, Tsukuba, Japan: ${ }^{2}$ Public Health, Department of Social and \\ Environmental Medicine, Osaka University Graduate School of Medicine, 2-2 Yamadaoka, Suita-shi, Osaka \\ 565-0871, Japan: ${ }^{3}$ Chikusei Kyowa Health Center, Chikusei, Japan: ${ }^{4}$ lkawa Municipal Office, Ikawa, Japan: \\ ${ }^{5}$ Osaka Medical Center for Health Science and Promotion, Osaka, Japan
}

Submitted 27 September 2007: Accepted 16 September 2008: First published online 14 November 2008

\begin{abstract}
Objective: To investigate long-term trends in dietary intakes of vitamins A, C and E in Japanese adults.

Design: Time series by community-based nutrition survey.

Setting: Two rural communities (Ikawa and Kyowa) between 1974 and 2001 in Japan.

Subjects: A total of 3713 men and 3726 women aged 40-69 years.

Methods: Dietary intake data were collected by the $24 \mathrm{~h}$ dietary recall.

Results: In Ikawa, mean intake of vitamin A ( $\beta$-carotene and retinol) increased by 13-40\%; vitamins $\mathrm{C}$ and $\mathrm{E}$ increased by approximately $23-33 \%$ among men and women from 1974-1977 to 1998-2000. In Kyowa, mean intake of vitamin A, primarily retinol, increased by 13-21\% among men and women; vitamin C from fruits decreased by $16 \%$ among men; and vitamin $\mathrm{E}$ increased by $29 \%$ among women from 1982-1986 to 1998-2001. Mean intake of vitamin E in the latest survey period was lower than the Adequate Intake among men and women in both communities. Generally, there were increased intakes of $\beta$-carotene and vitamin $\mathrm{C}$ from green/yellow and other vegetables; increased retinol intake from fish/shellfish, eggs, milk/dairy products and fats/oils; and increased vitamin $\mathrm{E}$ intake from green/yellow and other vegetables, fish/shellfish, eggs, milk/dairy products and fats/oils.

Conclusions: Mean intakes of the antioxidant vitamins A, C and E increased among middle-aged Japanese men and women between the 1970s and the 1990s except for decreased vitamin $\mathrm{C}$ among Kyowa men. The lower mean intake of vitamin $\mathrm{E}$ than the Adequate Intake should be considered a potential public health issue for the prevention of CVD.
\end{abstract}

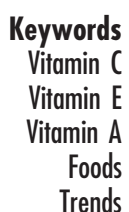

Vitamins with antioxidant properties may be protective against CVD and cancer ${ }^{(1-3)}$. Antioxidants can reduce the oxidative modification of LDL to affect blood cholesterol levels ${ }^{(1)}$ and to prevent oxidative damage to cells, thereby reducing the risk of cancer ${ }^{(4-8)}$

\footnotetext{
$\dagger$ Present affiliation: Nichirei Fresh Inc., Tokyo, Japan.

$\$$ Present affiliation: Department of Public Health, Social Medicine and Medical Informatics, Ehime University Graduate School of Medicine, Matsuyama, Japan

$\S$ Present affiliation: Chiba Prefectural Institute of Public Health, Chiba, Japan.
}

Higher serum levels of carotenoids such as $\alpha$ - and $\beta$-carotene have been associated with lower mortality from lung ${ }^{(9,10)}$ and colorectal cancers ${ }^{(11)}$ among Japanese men. Vitamin C was reported to lower blood pressure levels $^{(12)}$ and was inversely associated with the incidence ${ }^{(13)}$ of and mortality ${ }^{(14)}$ from stroke.

Intake of another major antioxidant vitamin, vitamin $\mathrm{E}$, has been associated with reduced risks of CHD and stroke when used in high doses ${ }^{(15-18)}$, although vitamin E supplementation had no effect on mortality from CVD and all causes in clinical trials ${ }^{(19,20)}$. A clinical trial of approximately 30000 Chinese adults demonstrated that a diet 
supplemented with $\beta$-carotene, vitamin $\mathrm{E}$ and Se reduced the risk of cancer by $13 \%{ }^{(21)}$. These findings suggest potential benefits of antioxidant vitamins for the prevention of CVD and cancer.

In 2000, the Ministry of Science and Education revised the Japanese standard food composition table for the first time in 18 years, to reflect the increasing diversification of Japanese dietary habits. Vitamins A, C and E were included in the new table, so that trends for the intake of these vitamins could be evaluated using the existing database of dietary surveys.

In the present study, we investigated long-term trends in dietary intakes of vitamins $\mathrm{A}, \mathrm{C}$ and $\mathrm{E}$, according to population-based surveys in two Japanese communities between 1974 and 2001.

\section{Methods}

The subjects in the present study comprised men and women aged from 40 to 69 years, living in Ikawa town, Akita Prefecture, and Kyowa town (presently a district of Chikusei city), Ibaraki Prefecture. Ikawa is located near the Sea of Japan in the north, where nearly half of the town is forest and rice-crop agriculture is the main industry. Kyowa is on a plain area in the mid-eastern region of Japan; this area is predominantly horticultural with a mix of rice-crop agriculture and light industry.

The nutrition surveys were conducted by $24 \mathrm{~h}$ dietary recall in approximately $10 \%$ of the participants in the annual cardiovascular risk surveys. Subjects aged over 70 years were excluded from the nutrition survey because the accuracy of recall-based data may decline with ageing. The participants in the cardiovascular risk surveys were recruited for the nutrition surveys, but were not pre-informed of the recruitment.

The surveys were conducted from 1974 to 2000 for Ikawa and from 1982 to 2001 for Kyowa. The survey data were collected during autumn in Kyowa and during spring in Ikawa. The nutrition survey term was stratified into seven time periods for Ikawa: 1974-1977, 1978-1981, 1982-1985, 1986-1989, 1990-1993, 1994-1997 and 1998-2000; and into four periods for Kyowa: 1982-1986, 1990-1993, 1994-1997 and 1998-2001. If a participant undertook the nutrition survey more than once during one survey period, we used the data from the earliest year in each survey period. The numbers of subjects by sex and time period in Ikawa and Kyowa are presented in Table 1.

The $24 \mathrm{~h}$ dietary recall method involves trained dietitians interviewing the study subjects on what they had eaten during the $24 \mathrm{~h}$ prior to examination. The same dietitians were used over the survey periods where possible to avoid fluctuations in interviewing technique over time. New dietitians were carefully trained before interviewing for the survey. In the interviews, actualized food models, pictures of food materials and dishes, and/ or real foods and dishes were shown to the participants to enable easy recall of their food intake. The same basic food models and interview forms were used throughout the surveys. Intake of green tea was included in the surveys from 1994. Rice and miso soup quantities were estimated by asking the subjects to put the usual amount of their intake into a bowl and this was then measured. We also investigated the intake frequencies of sixteen major foods and food groups per week to confirm that the foods included in the $24 \mathrm{~h}$ dietary recall were representative of the subject's usual diet. Survey periods encompassing special events such as a festival or celebration were excluded from the surveys. The interview took approximately $30 \mathrm{~min}$ per subject. We did not ask about the use of vitamin supplements because supplement use has been uncommon during the survey periods.

Nutrient intakes were estimated based on fifth revised edition of the Standard Tables of Food Composition in $\operatorname{Japan}^{(22)}$. The data were originally coded based on the fourth edition of the food composition tables between 1974 and 1999, and on the fifth edition between 2000 and 2001. Foods appearing for the first time in the fifth and fifth revised editions were rarely eaten by our study participants. The data on vitamins were total vitamin A $(\mu \mathrm{g}$ retinol equivalents $(\mathrm{RE}) / \mathrm{d}), \beta$-carotene $(\mu \mathrm{g} / \mathrm{d})$, vitamin $C(\mathrm{mg} / \mathrm{d})$ and $\alpha$-tocopherol $(\mu \mathrm{g} / \mathrm{d})$ as vitamin $\mathrm{E}$. It is possible that the amounts of vitamins $\mathrm{A}, \mathrm{C}$ and $\mathrm{E}$ contained in the same foods may have changed from the 1970s to the present, but we have no data to support this possibility. Therefore, we used the data in the fifth edition throughout the surveys.

The food composition tables provide nutritional data after cooking only for selected foods. Thus, we evaluated all data in the pre-cooked state to investigate long-term trends, although this may have introduced a systematic overestimation of nutrient intakes.

For primary trend analyses, we did not include dietary intake of green tea because this intake was not surveyed prior to 1994 . However, for the secondary analyses, we included vitamins A, C and E from green tea in the latest survey period, to estimate the true proportions of these nutrients in the total intakes. Persons who reported upper and lower $1 \%$ of these vitamins were excluded from the analyses ( $n$ 528).

Sex-specific age-adjusted mean values and standard errors of vitamin A, C and E intakes were calculated by analysis of covariance for each survey period as described above. We also evaluated intakes of these vitamins by major food group. Differences in mean values from the earliest survey period were determined using Dunnett's multiple comparison method. The SAS statistical software package version 9.13 (SAS Institute Inc., Cary, NC, USA) was used for statistical analysis. $P$ values less than $0 \cdot 05$ were regarded as statistically significant throughout the surveys. 


\section{Results}

The number of survey participants in each survey period was between 176 and 370 for men and between 132 and 325 for women in Ikawa, while the respective number in Kyowa was between 355 and 627 and between 433 and 572 (Table 1).

Age-adjusted mean ( $\mathrm{se})$ BMI $\left(\mathrm{kg} / \mathrm{m}^{2}\right)$ in the latest survey period (1998-2000 in Ikawa, 1998-2001 in Kyowa) was $23.9(0 \cdot 2)$ among men and $24 \cdot 3(0 \cdot 2)$ among women in Ikawa, and $23 \cdot 7(0 \cdot 1)$ among men and $23 \cdot 5(0 \cdot 2)$ among women in Kyowa. The proportion of subjects who drank more than one alcoholic drink per week was $86 \%$ among men and 9\% among women in Ikawa, and $74 \%$ among men and $11 \%$ among women in Kyowa.

Table 1 shows trends for sex-specific age-adjusted mean dietary intakes of vitamins $\mathrm{A}, \mathrm{C}$ and $\mathrm{E}$ in the two communities. Mean intake of total vitamin A increased by $13 \%$ among men and $40 \%$ among women; $\beta$-carotene increased by $2 \%$ among men and $31 \%$ among women; and retinol increased by $56 \%$ among men and $105 \%$ among women from 1974-1977 to 1998-2000 in Ikawa. Among men and women in Kyowa, mean intake of total vitamin A increased by $13 \%$ for men and $21 \%$ for women; retinol increased by $16 \%$ for men and $29 \%$ for women, but $\beta$-carotene did not change between 1982-1986 and 1998-2001.

Mean intake of vitamin C increased by $23 \%$ among men and 29\% among women from 1974-1977 to 1978-1981, and plateaued thereafter in Ikawa. In Kyowa, it decreased by $16 \%$ among men, but did not change among women from 1982-1986 to 1990-1993.

Mean intake of vitamin E increased by $34 \%$ among men and 33\% among women from 1974-1977 to 1982-1985, and plateaued thereafter in Ikawa. In Kyowa, mean intake of vitamin $\mathrm{E}$ did not change among men, but increased by 8\% among women from 1982-1986 to 1998-2001.

Table 2 shows trends for sex-specific age-adjusted mean dietary intakes of vitamins $\mathrm{A}, \mathrm{C}$ and $\mathrm{E}$ by food group in the two communities. Mean intake of $\beta$-carotene from green/yellow vegetables, a primary food source, increased among men from 1974-1977 to 1982-1985, and plateaued thereafter in Ikawa, whereas that from fruits and algae decreased among men and women from 1974-1977 to 1998-2000 in Ikawa. In Kyowa, mean intake of $\beta$-carotene from fruits decreased among men, but did not change substantially among women from 1982-1986 to $1990-1993$.

Mean intake of retinol from fish/shellfish increased among men and women from 1974-1977 to 1998-2000 in

Table 1 Trends for sex-specific age-adjusted mean dietary intakes of vitamins A, C and E in men and women aged 40-69 years in Ikawa and Kyowa, Japan

\begin{tabular}{|c|c|c|c|c|c|c|c|c|c|c|c|c|}
\hline \multirow[b]{2}{*}{ Sex/community } & \multirow{2}{*}{$\begin{array}{l}\text { Survey } \\
\text { years }\end{array}$} & \multirow{2}{*}{$\begin{array}{l}\text { No. of } \\
\text { subjects }\end{array}$} & \multicolumn{2}{|c|}{ Total vitamin A ( $\mu \mathrm{g} R E / d)$} & \multicolumn{2}{|c|}{$\beta$-Carotene $(\mu \mathrm{g} / \mathrm{d})$} & \multicolumn{2}{|c|}{ Retinol $(\mu \mathrm{g} / \mathrm{d})$} & \multicolumn{2}{|c|}{ Vitamin C (mg/d) } & \multicolumn{2}{|c|}{ Vitamin $E(\mathrm{mg} / \mathrm{d})$} \\
\hline & & & Mean & SE & Mean & SE & Mean & SE & Mean & SE & Mean & SE \\
\hline \multicolumn{13}{|l|}{ Men } \\
\hline \multicolumn{13}{|l|}{ Ikawa } \\
\hline & 1974-1977 & 306 & 506 & $22 \cdot 2$ & 4470 & $198 \cdot 3$ & 129 & $14 \cdot 3$ & 81 & $3 \cdot 4$ & $5 \cdot 9$ & $0 \cdot 17$ \\
\hline & 1978-1981 & 176 & 515 & $29 \cdot 1$ & 4427 & $259 \cdot 9$ & 138 & $18 \cdot 7$ & $100^{\star *}$ & $4 \cdot 5$ & $6 \cdot 1$ & 0.22 \\
\hline & 1982-1985 & 370 & $615^{\star \star}$ & $20 \cdot 0$ & $5503^{\star \star *}$ & $179 \cdot 3$ & 150 & $12 \cdot 9$ & $110^{\star * \star}$ & $3 \cdot 1$ & $7 \cdot 9^{\star \star \star}$ & $0 \cdot 15$ \\
\hline & $1986-1989$ & 308 & 563 & $22 \cdot 0$ & $5375^{\star \star}$ & $197 \cdot 1$ & 170 & $14 \cdot 2$ & $108^{\star \star \star}$ & $3 \cdot 4$ & $7 \cdot 4^{\star \star \star}$ & $0 \cdot 16$ \\
\hline & 1990-1993 & 262 & $606^{*}$ & $23 \cdot 9$ & $5252^{*}$ & $213 \cdot 7$ & $202^{\star \star}$ & $15 \cdot 4$ & $98^{\star \star}$ & $3 \cdot 7$ & $7 \cdot 3^{\star \star \star}$ & $0 \cdot 18$ \\
\hline & $1994-1997$ & 281 & $599^{*}$ & $23 \cdot 2$ & $5591^{\star \star \star}$ & $207 \cdot 9$ & 165 & $15 \cdot 0$ & $106^{\star \star \star}$ & $3 \cdot 6$ & $7 \cdot 3^{\star \star \star}$ & $0 \cdot 17$ \\
\hline & 1998-2000 & 224 & 571 & $25 \cdot 8$ & 4559 & $230 \cdot 5$ & $201^{\star \star}$ & $16 \cdot 6$ & $97^{*}$ & $3 \cdot 9$ & $7 \cdot 0^{\star \star \star}$ & $0 \cdot 19$ \\
\hline \multicolumn{13}{|l|}{ Kyowa } \\
\hline & 1982-1986 & 627 & 436 & $13 \cdot 1$ & 3752 & $119 \cdot 5$ & 119 & $7 \cdot 4$ & 137 & $3 \cdot 7$ & $6 \cdot 4$ & $0 \cdot 12$ \\
\hline & $1990-1993$ & 355 & 426 & $17 \cdot 4$ & $3148^{* *}$ & $158 \cdot 4$ & $170^{\star * *}$ & $9 \cdot 8$ & $116^{\star \star}$ & $4 \cdot 9$ & $6 \cdot 4$ & $0 \cdot 16$ \\
\hline & 1994-1997 & 381 & 448 & $16 \cdot 8$ & 3609 & $153 \cdot 2$ & $149^{\star}$ & $9 \cdot 4$ & 129 & $4 \cdot 8$ & $6 \cdot 7$ & $0 \cdot 16$ \\
\hline & $1998-2001$ & 423 & $491^{*}$ & $15 \cdot 9$ & 3682 & $145 \cdot 2$ & 138 & $8 \cdot 9$ & $115^{\star \star \star}$ & $4 \cdot 5$ & $6 \cdot 6$ & $0 \cdot 15$ \\
\hline \multicolumn{13}{|l|}{ Women } \\
\hline & $1974-1977$ & 253 & 435 & $23 \cdot 9$ & 4106 & $203 \cdot 9$ & 83 & $16 \cdot 4$ & 90 & $3 \cdot 8$ & $5 \cdot 5$ & $0 \cdot 16$ \\
\hline & 1978-1981 & 132 & 490 & 32.9 & 4346 & $281 \cdot 1$ & 123 & $22 \cdot 7$ & $116^{\star \star \star \star}$ & 5.2 & $6 \cdot 1$ & 0.23 \\
\hline & $1982-1985$ & 273 & $578^{* * *}$ & $22 \cdot 9$ & $5100^{\text {** }}$ & $195 \cdot 3$ & $145^{\star}$ & $15 \cdot 7$ & $119^{* \star *}$ & 3.6 & $7 \cdot 3^{\star \star \star}$ & $0 \cdot 16$ \\
\hline & $1986-1989$ & 266 & $547^{* *}$ & $23 \cdot 2$ & $5247^{\star \star *}$ & $197 \cdot 9$ & $157^{\star \star}$ & $16 \cdot 0$ & $114^{\star \star \star}$ & $3 \cdot 7$ & $7 \cdot 0^{\star \star \star}$ & $0 \cdot 16$ \\
\hline & 1990-1993 & 325 & $576^{\star \star \star}$ & $21 \cdot 0$ & $5437^{\star \star \star}$ & $179 \cdot 4$ & $163^{\star \star}$ & $14 \cdot 5$ & $123^{\star \star \star}$ & $3 \cdot 3$ & $7 \cdot 2^{\star \star \star}$ & $0 \cdot 14$ \\
\hline & 1994-1997 & 318 & $626^{\star \star *}$ & $21 \cdot 2$ & $5417^{\star \star \star}$ & $181 \cdot 0$ & $185^{\star * \star}$ & $14 \cdot 6$ & $114^{\star \star \star}$ & $3 \cdot 4$ & $6 \cdot 9^{\star \star \star \star}$ & $0 \cdot 14$ \\
\hline & 1998-2000 & 242 & $609^{* \star \star}$ & $24 \cdot 3$ & $5390^{* \star *}$ & $207 \cdot 5$ & $170^{\star \star}$ & $16 \cdot 7$ & $121^{\star \star \star}$ & 3.9 & $6 \cdot 7^{\star \star \star}$ & $0 \cdot 17$ \\
\hline \multicolumn{13}{|l|}{ Kyowa } \\
\hline & 1982-1986 & 572 & 499 & $13 \cdot 7$ & 4525 & $124 \cdot 7$ & 119 & $7 \cdot 3$ & 154 & $4 \cdot 0$ & $6 \cdot 6$ & $0 \cdot 12$ \\
\hline & 1990-1993 & 433 & 515 & $15 \cdot 7$ & 4230 & $143 \cdot 3$ & $157^{\star \star}$ & $8 \cdot 4$ & 154 & $4 \cdot 6$ & $6 \cdot 7$ & $0 \cdot 14$ \\
\hline & 1994-1997 & 449 & 518 & $15 \cdot 5$ & 4592 & $140 \cdot 9$ & 135 & $8 \cdot 3$ & 156 & $4 \cdot 6$ & $6 \cdot 6$ & $0 \cdot 14$ \\
\hline & 1998-2001 & 463 & $603^{\star \star \star}$ & $15 \cdot 2$ & 4533 & $138 \cdot 5$ & $153^{\star *}$ & $8 \cdot 1$ & 150 & $4 \cdot 5$ & $7 \cdot 1^{*}$ & $0 \cdot 14$ \\
\hline
\end{tabular}

$R E$, retinol equivalents.

Intake of green tea was not taken into account; intakes of nutrients were evaluated in conditions before cooking

Mean values were significantly different from those of the first survey: ${ }^{\star} P<0.05,{ }^{\star \star} P<0.01,{ }^{\star \star \star} P<0.001$. 


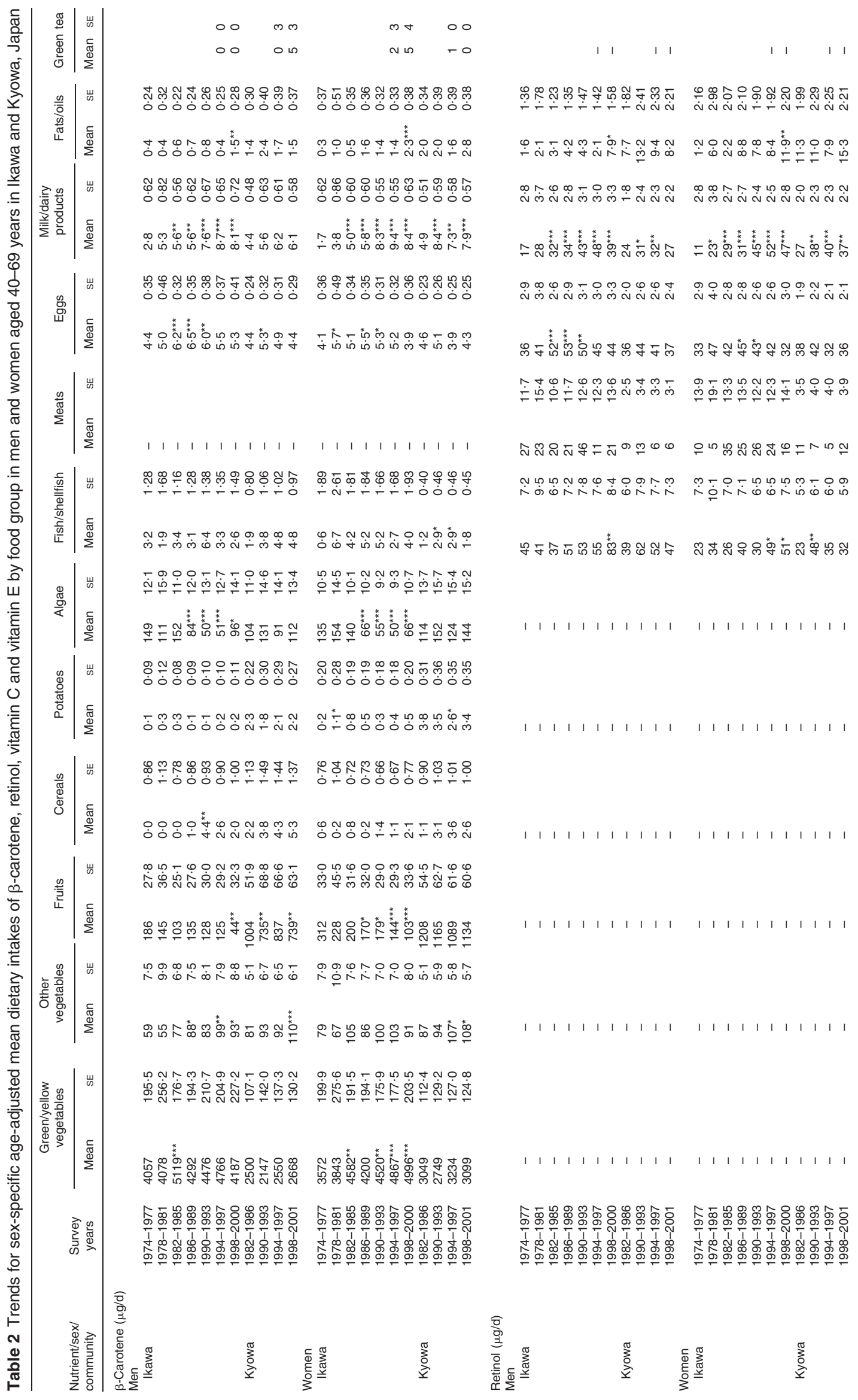




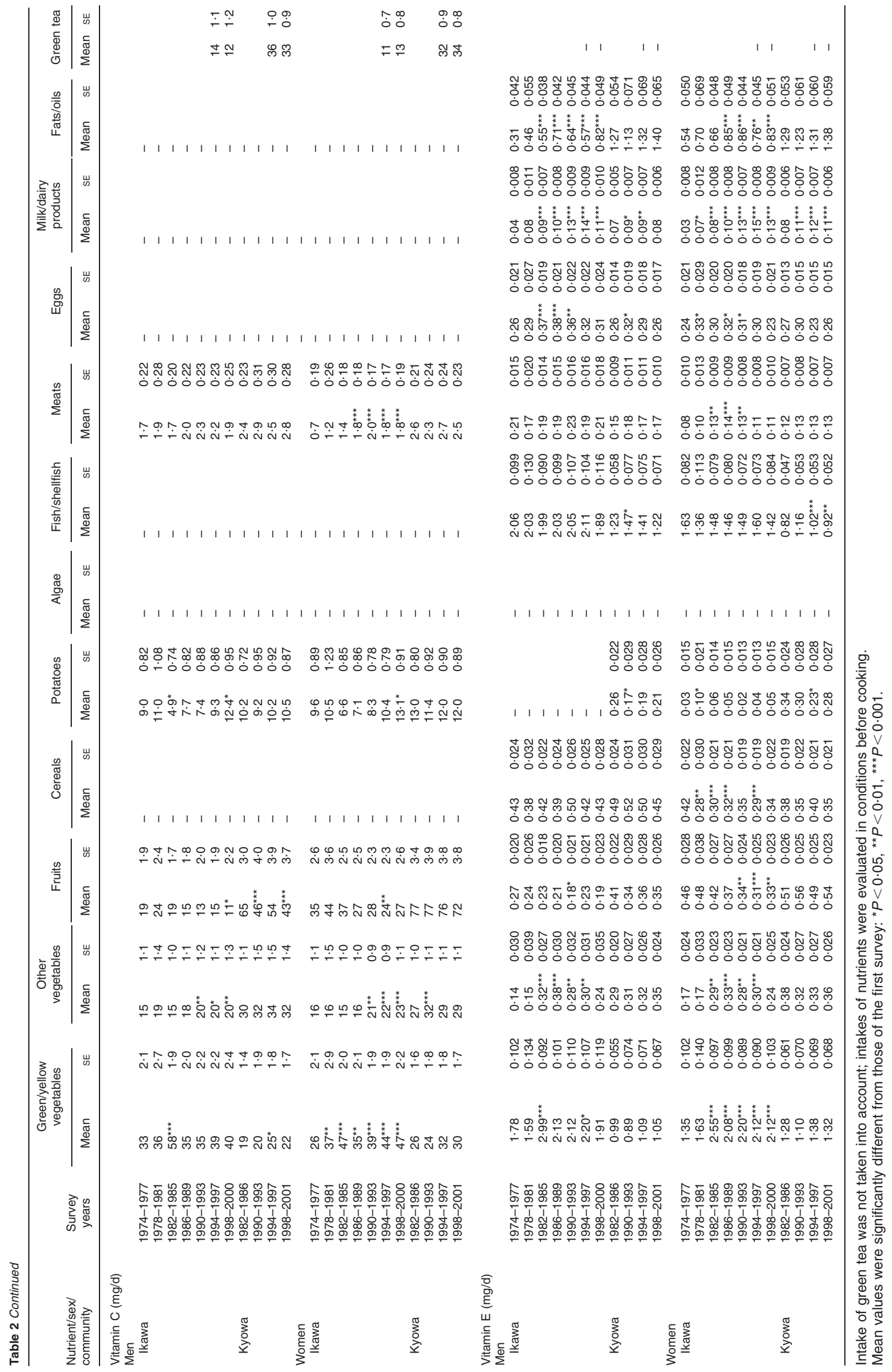


Ikawa, and did not change substantially among men and women from 1982-1986 to 1990-1993 in Kyowa. Mean intake of retinol from, eggs, milk/dairy products and fats/ oils increased among men and women from 1974-1977 to 1998-2000 in Ikawa. In Kyowa, mean intake of retinol from milk/dairy products increased from 1982-1986 to 1990-1993, and then plateaued thereafter.

Mean intake of vitamin C from green/yellow and other vegetables, primary food sources, increased among men and women from 1974-1977 to 1982-1985 and plateaued thereafter in Ikawa, while that from fruits tended to decrease after the 1980s. In Kyowa, mean intake of vitamin $\mathrm{C}$ from green/yellow and other vegetables and fruits did not change substantially among men and women from 1982-1986 to 1998-2001.

Mean intake of vitamin E from green/yellow and other vegetables and fats/oils increased among men and women from 1974-1977 to 1982-1985, and plateaued thereafter in Ikawa, while intake from these foods did not change substantially among men and women in Kyowa.

The proportions of $\beta$-carotene intake according to food group in the latest survey period (1998-2001 for Ikawa, 1998-2000 for Kyowa) are shown in Fig. 1. The major food sources for $\beta$-carotene intake were green/yellow (92-93\%) and other vegetables (1-2\%) and fruits (1-2\%) among men and women in Ikawa, with 68-72\%, 3\% and $20-25 \%$, respectively, among men and women in Kyowa. The retinol intake comprised 30-41\% from fish/ shellfish, 19-22\% from eggs and 19-28\% from milk/dairy products among men and women in Ikawa. The respective proportions in Kyowa were 21-34\%, 24-27\% and 20-24\%.

Vitamin C intake consisted of 35-37\% from green/ yellow vegetables, $17-18 \%$ from other vegetables, $10-20 \%$ from fruits and 10-11\% from green tea among men and women in Ikawa. The respective proportions in Kyowa were 15-16\%, 16-22\%, 29-39\% and 19-22\%.

The vitamin E intake comprised $27-31 \%$ from green/ yellow vegetables, 3\% from other vegetables, 21-27\% from fish/shellfish and 11-12\% from fats/oils among men and women in Ikawa. The respective proportions in Kyowa were $15-18 \%, 6 \%, 13-18 \%$ and $20-21 \%$.

\section{Discussion}

The present study of long-term nutritional trends in Japan revealed that both men and women in Ikawa had increased dietary intakes of $\beta$-carotene and vitamin $\mathrm{C}$, primarily from green/yellow and other vegetables; increased intake of retinol from fish/shellfish, eggs, milk/ dairy products and fats/oils; and increased intake of vitamin E from green/yellow and other vegetables, milk/ dairy products and fats/oils between the 1970s and the 1990s. In Kyowa, mean intake of retinol from fish/shellfish and milk/dairy products increased among men and women; while mean intake of vitamin C from fruits decreased among men between the 1980s and the 1990s.

Ikawa comprises areas of plains and mountains where people have traditionally worked mainly on rice farms. New factories for heavy industry were founded in the late 1970 s and many farmers changed to work in these factories. According to local government statistics, $67 \%$ of the population worked on farms and $12 \%$ in factories in 1975 , but this had changed to $41 \%$ and $42 \%$, respectively, by 1980 . Consequently, the mean income of people in this community increased from the 1970s to the 1980s, which improved eating habits in terms of nutrition. In contrast, Kyowa is located on the plains where a large percentage of people worked on fruit and vegetable farms or for light-industry companies; there have been no substantial changes in industry since the 1980s.

Mean intakes of vitamins A, C and E in Ikawa and Kyowa were similar to those of the national samples in Japan. According to the national nutritional survey ${ }^{(23,24)}$, the daily per capita intake of total vitamin A increased from 1974 (552 $\mu \mathrm{g}$ RE) to 2001 (981 $\mu \mathrm{g} \mathrm{RE}$ ). The daily per capita intake of vitamin C remained over $100 \mathrm{mg}$ : $120 \mathrm{mg}$ in 1974 and $106 \mathrm{mg}$ in 2001. The daily per capita intake of vitamin E was $8.5 \mathrm{mg}$ in $2001^{(24)}$.

For ages 30-69 years, the Estimated Average Requirement for total vitamin A is $500-550 \mu \mathrm{g} \mathrm{RE} / \mathrm{d}$ for men and $450 \mu \mathrm{g}$ $\mathrm{RE} / \mathrm{d}$ for women, and that for vitamin $\mathrm{C}$ is $55 \mathrm{mg} / \mathrm{d}$ for both sexes. The Adequate Intake of vitamin $\mathrm{E}$ is $8-9 \mathrm{mg} / \mathrm{d}$ for men and $8 \mathrm{mg} / \mathrm{d}$ for women ${ }^{(25)}$. Therefore, mean intakes of vitamins $\mathrm{A}$ and $\mathrm{C}$ in the present study samples were higher than the Estimated Average Requirement except for slightly lower vitamin A in Kyowa men. Mean intake of vitamin E was lower than the Adequate Intake among men and women in both communities.

Mean daily intakes of vitamins $\mathrm{C}$ among Americans according to the National Health and Nutrition Examination Survey (NHANES) in 1999-2000(26) were $107 \mathrm{mg}$ among men aged 40-59 years, $110 \mathrm{mg}$ among men aged $\geq 60$ years, $91 \mathrm{mg}$ among women aged 40-59 years and $99 \mathrm{mg}$ among women aged $\geq 60$ years. The respective intakes of vitamin E were $10.4 \mathrm{mg}, 9.2 \mathrm{mg}, 9.1 \mathrm{mg}$ and $7.6 \mathrm{mg}$. Mean intakes of vitamin A could not be compared with the US data because of different methods of calculation. That report and the present findings suggest that the mean intake of vitamin $\mathrm{C}$ around 2000 was similar for men and higher for women, and that the mean intake of vitamin E was lower for both sexes of the Japanese samples than for the US samples.

The strength of the present study lay in the $24 \mathrm{~h}$ dietary recall method used in the surveys, with a sample large enough to statistically estimate sex-specific long-term trends. However, our study has several limitations. First, we evaluated nutrient intakes only for raw foods because there was no systematic database available to assess nutrient loss by cooking. Since the survival proportion of vitamins $\mathrm{C}$ in vegetables following cooking is approximately $50-90 \%{ }^{(22)}$, 

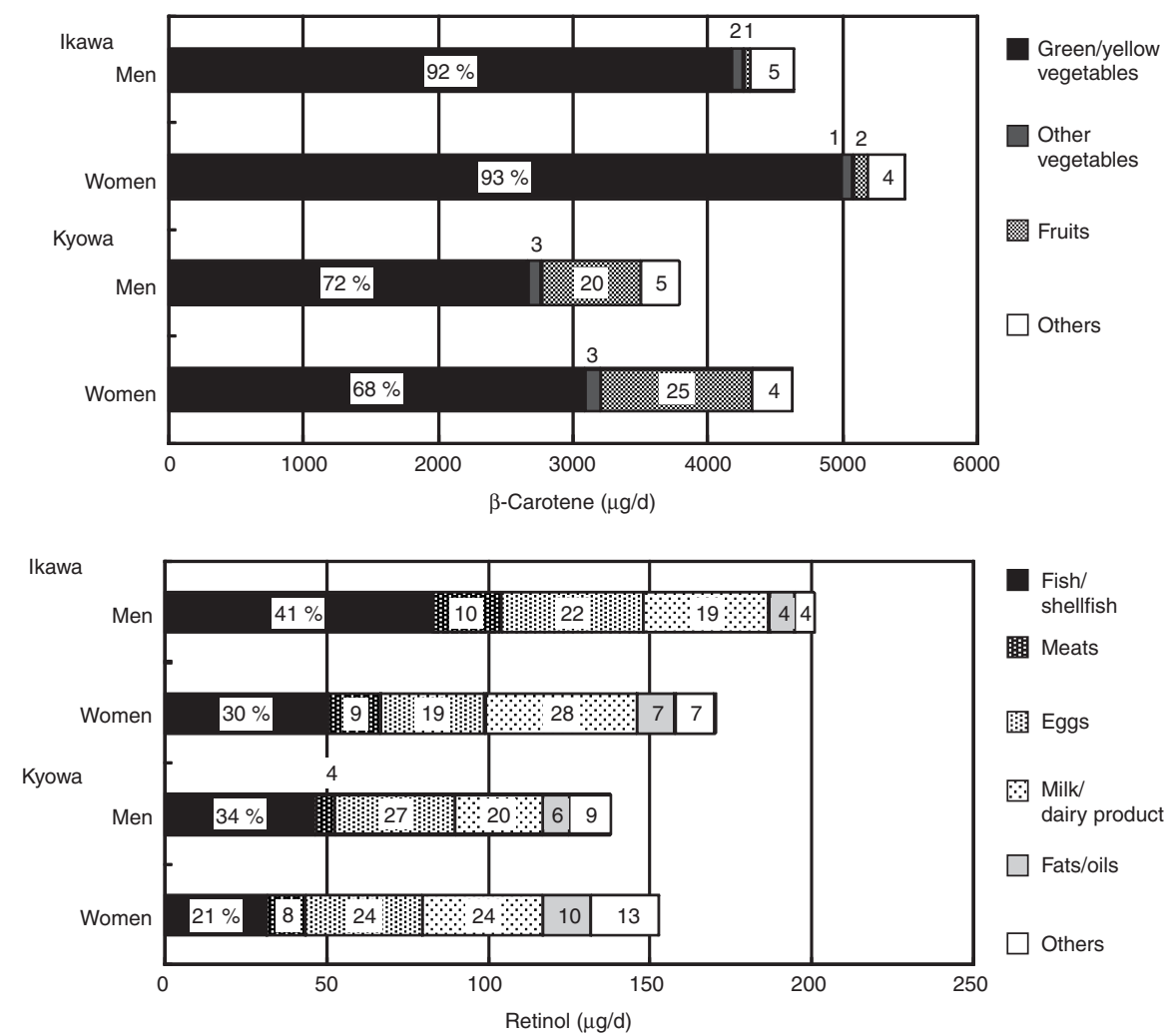

Fish

shellfish

聞 Meats

缃 Eggs

[.] Milk/

dairy products

$\square$ Fats/oils

$\square$ Others

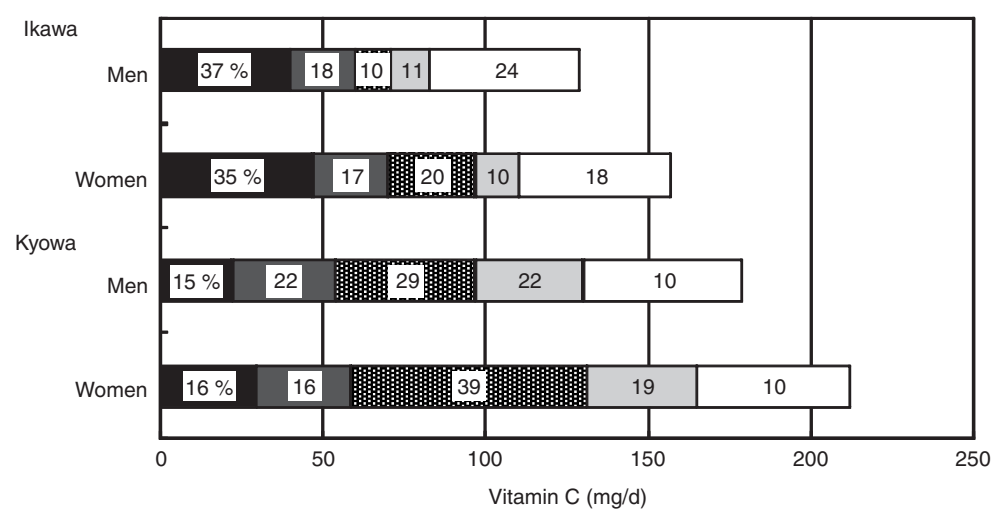

Green/yellow vegetables

Other

vegetables

䁅 Fruits

$\square$ Green tea

$\square$ Others

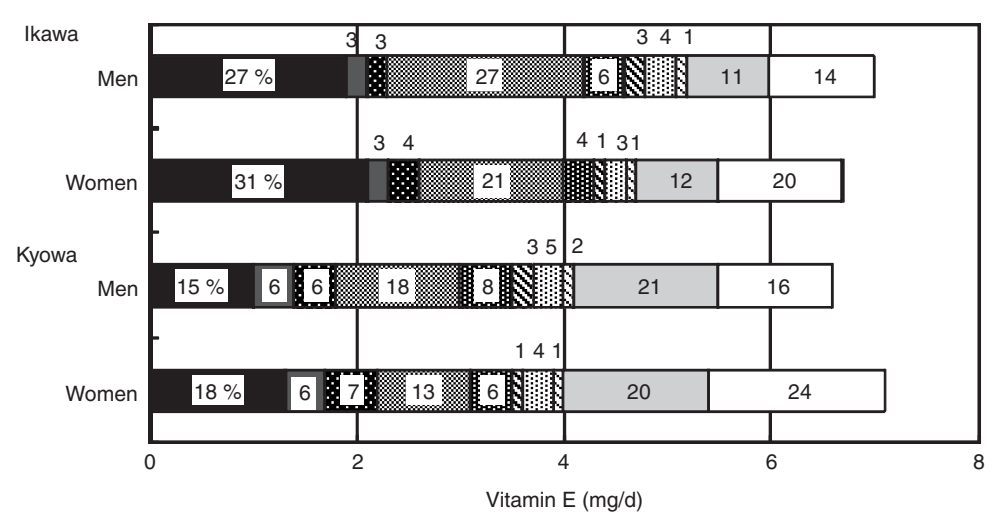

Green/yellow vegetables

Other

vegetables

$\therefore$ Fruits

Fish/

shellfish

闻 Cereals

Neats

珼 Eggs

D. Milk/

$\square$ Fats/oils

$\square$ Others

Fig. 1 Sex-specific age-adjusted mean dietary intakes of $\beta$-carotene, retinol, vitamin $C$ and vitamin $E$ by food group, in men and women aged 40-69 years in Ikawa and Kyowa, Japan, in the latest survey period (1998-2000 in Ikawa, 1998-2001 in Kyowa). The numbers in bars are the proportions of the vitamin intakes by food group 
dietary intake of vitamin C may be overestimated systematically in the present study. Second, we did not have data on vitamin supplements in addition to dietary intake. However, this limitation is unlikely to have a large impact on the prediction of risk trends for CVD because the use of vitamin supplements may be low in these communities as vitamin supplements have been available for purchase in convenience stores only since 2004 .

In summary, we investigated long-term trends in dietary intakes of vitamins A, C and E among Japanese middleaged adults in two rural communities. Increases occurred for vitamins A, C and E between the 1970s and the 1990s except for decreased vitamin $\mathrm{C}$ among Kyowa men. The lower mean intake of vitamin $\mathrm{E}$ than the Adequate Intake should be considered a potential public health issue for the prevention of CVD.

\section{Acknowledgements}

Conflicts of interest: There are no conflicts of interest.

Funding: The study was supported by a Grant-in-Aid for Research B (11470103 in 1999 to 2001) and Research A (14207019 in 2002 to 2005) from the Japan Society for the Promotion of Science.

Author contributions: Y.K. analysed the data and wrote the first draft. H.I. designed the study, chaired the steering committee, managed the study and edited the manuscript. S.I. and K.M. assisted in conducting the analysis design and preparing the manuscript. M.I., M.O., K. Yokota, S.M., T.Y., M. Kishi and M. Kurokawa participated in the field surveys. M.U. and E.M. analysed the data. K. Yamagishi, T.T. and S.S. managed the surveillance, analysed and edited the manuscript. T.S. was a member of the steering committee who monitored and managed the study.

\section{References}

1. Witztum JL (1994) The oxidation hypothesis of atherosclerosis. Lancet 344, 793-795.

2. Marchioli R (1999) Antioxidant vitamins and prevention of cardiovascular disease: laboratory, epidemiological and clinical trial data. Pharmacol Res 40, 227-238.

3. Hennekens CH, Gaziano JM, Manson JE \& Buring JE (1995) Antioxidant vitamin-cardiovascular disease hypothesis is still promising, but still unproven: the need for randomized trials. Am J Clin Nutr 62, 1377-1380.

4. Edes TE \& Gysbers DS (1993) Carcinogen-induced tissue vitamin A depletion. Potential protective advantages of $\beta$-carotene. Ann N Y Acad Sci 686, 203-212.

5. Chew BP \& Park JS (2004) Carotenoid action on the immune response. J Nutr 134, 257-261.

6. Kohlmeier L, Simonsen N \& Mottus K (1995) Dietary modifiers of carcinogenesis. Environ Health Perspect 103, 177-184.

7. Valko M, Izakovic M, Mazur M, Rhodes CJ \& Telser J (2004) Role of oxygen radicals in DNA damage and cancer incidence. Mol Cell Biochem 266, 37-56.
8. Yoshikawa T \& Kokura S (2003) Free radical and cancer prevention. Igaku no Ayumi 204, 20-23.

9. Ito Y, Wakai K, Suzuki K et al. (2003) Serum carotenoids and mortality from lung cancer: a case-control study nested in the Japan Collaborative Cohort (JACC) study. Cancer Sci 94, 57-63.

10. Ito Y, Wakai K, Suzuki K et al. (2005) Lung cancer mortality and serum levels of carotenoids, retinol, tocopherols, and folic acid in men and women: a case-control study nested in the JACC Study. J Epidemiol 15, 140-149.

11. Wakai K, Suzuki K, Ito Y et al. (2005) Serum carotenoids, retinol, and tocopherols, and colorectal cancer risk in a Japanese cohort: effect modification by sex for carotenoids. Nutr Cancer 51, 13-24.

12. Trout DL (1991) Vitamin C and cardiovascular risk factors. Am J Clin Nutr 53, 322S-325S.

13. Yokoyama T, Date C, Kokubo Y, Yoshiike N, Matsumura Y \& Tanaka H (2000) Serum vitamin C concentration was inversely associated with subsequent 20 -year incidence of stroke in a Japanese rural community. The Shibata study. Stroke 31, 2287-2294.

14. Gale CR, Martyn CN, Winter PD \& Cooper C (1995) Vitamin $C$ and risk of death from stroke and coronary heart disease in cohort of elderly people. BMJ 310, 1563-1566.

15. Stampfer MJ \& Rimm EB (1995) Epidemiologic evidence for vitamin $\mathrm{E}$ in prevention of cardiovascular disease. Am J Clin Nutr 62, 1365-1369.

16. Voko Z, Hollander M, Hofman A, Koudstaal PJ \& Breteler MM (2003) Dietary antioxidants and the risk of ischemic stroke: the Rotterdam Study. Neurology 61, $1273-1275$.

17. Dagenais GR, Marchioli R, Yusuf S \& Tognoni G (2000) $\beta$-Carotene, vitamin $C$, and vitamin $\mathrm{E}$ and cardiovascular diseases. Curr Cardiol Rep 2, 293-299.

18. Gaziano JM (2004) Vitamin E and cardiovascular disease: observational studies. Ann N Y Acad Sci 1031, 280-291.

19. Miller ER 3rd, Pastor-Barriuso R, Dalal D, Riemersma RA, Appel LJ \& Guallar E (2005) Meta-analysis: high-dosage vitamin E supplementation may increase all-cause mortality. Ann Intern Med 142, 37-46.

20. Lee IM, Cook NR, Gaziano JM, Gordon D, Ridker PM, Manson JE, Hennekens CH \& Buring JE (2005) Vitamin E in the primary prevention of cardiovascular disease and cancer: the Women's Health Study: a randomized controlled trial. JAMA 294, 56-65.

21. Blot WJ, Li JY, Taylor PR et al. (1993) Nutrition intervention trials in Linxian, China: supplementation with specific vitamin/mineral combinations, cancer incidence, and disease-specific mortality in the general population. J Natl Cancer Inst 85, 1483-1492.

22. Japanese Science and Technology Agency (2006) Standard Tables of Food Composition in Japan, 5th revised ed. Tokyo: National Printing Bureau.

23. Ministry of Health, Labour and Welfare (1977) Annual Report of the National Health and Nutrition Survey in Japan, 1974. Tokyo: Daiichi Shuppan.

24. Ministry of Health, Labour and Welfare (2003) Annual Report of the National Health and Nutrition Survey in Japan, 2001. Tokyo: Daiichi Shuppan.

25. Ministry of Health, Labour and Welfare (2005) Dietary Reference Intakes for Japanese, 2005. Tokyo: Daiichi Shuppan.

26. Ervin RB, Wright JD, Wang CY \& Kennedy-Stephenson J (2004) Dietary intake of fats and fatty acids for the United States population: 1999-2000. Adv Data 348, $1-6$. 